\title{
THE IMPACT OF THE CONSEQUENCES OF THE COVID-19 PANDEMIC ON THE SOCIAL SECURITY OF UKRAINE
}

\author{
Irada Dzhalladova ${ }^{1}$, Oleh Kaminsky², Oleksandr Lutyj ${ }^{3}$
}

\author{
${ }^{1,2,3}$ Vadym Hetman Kyiv National Economic University, Kyiv, Ukraine
}

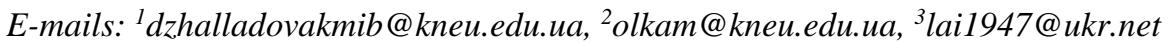

Received: 15 July 2021; $\quad$ Accepted: 05 August 2021; Online Published: 09 August 2021

\begin{abstract}
:
The aim of the work is a systematic analysis of logical, structural connections between different threats to sociocybernetic security. We include in the consideration a wide range of different components, different understandings of social security: security of technical systems, security of cyberspace, security of cyber-physical systems and so on. Everything is almost not studied and not studied in general. An important aspect of state capacity is analyzed in the work with the help of the constructed mathematical model: the problem of threats to social security. Depending on the condition (stable or unstable), there is a system that is characterized by a numerical integrated indicator (number of patients, number of those who passed the test, number of occupied beds in the hospital), social security in a broad and narrow sense, can to be considered and considered as being in a state of threat or protected. Hundreds of thousands of different methods and tools have been built over the millennia, but in modern conditions none is ready. Actually, the situation with COVID-19 showed it. The flexibility of mind and a combination of different methods is the only key to modelling different processes, including security-related processes. In addition, it should be noted that IT tools are not always universal. In modelling these processes, the balance of knowledge in the field of economics, politics, IT, cybersecurity, etc. is important. It is also important to understand that the initial stages of creating algorithms for the protection of the socio-cybernetic system should be considered in the usual senseunderstanding of social security. To do this, it is necessary to establish links between different processes of subsystems.
\end{abstract}

Keywords: social security, resilience, consequences of a pandemic, Covid-19 pandemic, cybersecurity.

JEL classification: A14, C51, J28

Citation:

Dzhalladova, I., Kaminsky, O., Lutyj, O. (2021). The impact of the consequences of the Covid-19 pandemic on the social security of Ukraine. Access to science, business, innovation in digital economy, ACCESS Press, 2(3): 252-260. https://doi.org/10.46656/access.2021.2.3(4)

\section{INTRODUCTION}

The impact of the COVID-19 pandemic on global processes is enormous and it is constantly intensifying and becoming more complicated: from the crisis in the world economy to the breakdown of personal human relations. So far, no country, no business, no community, no family, no person has escaped the consequences of a situation that has suddenly (let's say the term probability theory happened). In addition to the direct impact of the coronavirus on human health and safety, the economic, social, demographic, environmental, behavioral, political and institutional consequences of the pandemic have been and continue to be profound. 
The COVID-19 pandemic is forcing the world to maintain social security and constantly face global challenges to real life. The use of factual data on the consequences of the pandemic by the state leadership, the study of support processes for responding to the COVID-19 pandemic will contribute to the adoption of scientifically sound decisions in the fields of economy, health and security of the state. This in turn will ensure a more humane and equitable policy for all and minimize the destructive impact of pandemics on the poor, vulnerable and vulnerable.

Analysis of recent research and publications. The issue of linking pandemics to threats to social security gained popularity in the 1990s. In 1995, the World Health Assembly (WHO) agreed to revise the International Health Regulations (IHR), the only international legal framework governing how the WHO and its Member States should respond to outbreaks of infectious diseases, on the basis that that the revision was necessary to take "effective account of the threats posed by the international spread of new and recurrent diseases" (World Health Organization, 1995). In 2005, the revised IHRs were adopted as WHO Resolution 58.3 (World Health Organization, 2005). Article 2 of the resolution emphasizes that the scope and choice of IHR instruments is to "prevent, protect, control and ensure public health responses to the international spread of the disease by any means comparable and limited to public health risks".

The study Buckley, Clem \& Herron (2020) notes that in addition to the devastating and widely discussed humanitarian and economic consequences of the COVID-19 pandemic, the current global crisis also exacerbates social security issues related to governments' shortcomings in ensuring the well-being of their citizens. their territory and receive funds for the survival of the population.

Study Andrea Riccardo Migone (2020) discusses the relationship between social policy characteristics and the success of the "smoothing curve" of COVID-19 infection, a widely accepted measure containing the worst medical outcomes of a pandemic. Although some cases require careful and detailed analysis for proper unpacking, the study finds that the best correlation is found in the study of the choice model associated with active or reactive approaches to the implementation of containment measures. This is especially evident for countries that have either very low or very high levels of infection per million people.

In their work, scientists K.Mizumoto \& G. Chowell (2020) assessed the risk of death from COVID-19 in Wuhan, as well as other parts of China, except Wuhan Province, taking into account the time delay to assess the severity of the epidemic in the country . Death risk estimates in Wuhan reached $12 \%$ at the epicenter of the epidemic and $\approx 1 \%$ in other, more affected areas. Increased death risk assessments have been identified as linked to the destruction of the health care system, and the effective role of enhanced health measures, including social distancing and restraint, has been emphasized.

Hoang Pham (2020) discussed a clear model function to estimate the total number of deaths among the population, and in particular to estimate the total number of deaths in the United States due to the current Covid-19 virus. The author compares the simulation results with two existing models based on the new criteria. The results showed that the proposed model was more accurate than the other two related models based on US Covid-19 mortality data. 
In the work of B. Yan, J. Wang, Z. Zhang, X. Tang, Y. Zhou et al. (2020) to solve the problem of predicting mortality from pandemics, an improved method for predicting confirmed deaths based on the neural network LSTM (Long-Short Term Memory). The paper compares the deviations between the experimental results of the advanced forecasting model LSTM and digital forecasting models (such as logistics equations and Hill equations) with real data as a reference. Experiments show that the proposed approach has fewer deviations from the forecast and a better adaptation effect.

The COVID-19 pandemic creates an environment for the development of cybercrime. Decreased vigilance among the population, anxiety disorders, work from home, congestion on the Internet lead to an increase in the flow of cybercrime. Companies that are engaged in the management of day-to-day operations in times of crisis do not pay due attention to the increased threats to information security that arise as a result of these exceptional circumstances.

For companies, teleworking is a risk factor to consider. The risk of attack on information systems, as well as networks, which are in great demand for remote work, is significant. Access to confidential and financial information, document fraud, supply chain adjustments, including food, increased network requirements caused by quarantine measures are all potentially serious consequences for the security system. In this context, competent authorities also need practical guidance on limiting cybersecurity risks to humans and society as a whole. To reduce the spread of COVID-19 and stop the epidemic, global, social and local security authorities need timely and up-to-date data and model forecasts to inform about prevention, control and distancing measures. Policymakers will also need data on behavioral and biomedical interventions during and after a pandemic to reduce the devastating effects, especially on the most vulnerable.

If security is understood as the absence of threats and resilience to threats in cyberspace, then social security in the digital society should be considered as a multilevel structure. In turn, each of the components also has its levels (Fig. 1):

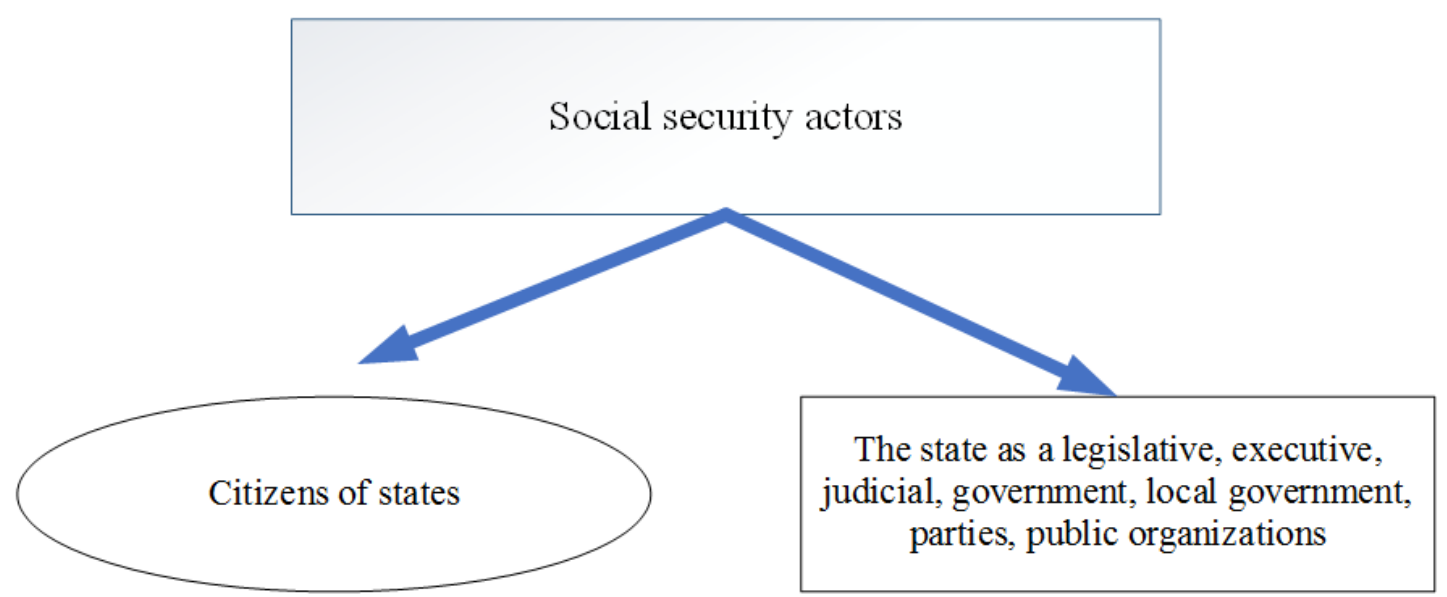

Fig. 1. Subjects of social security

source: developed by the authors 
To imagine the effect of this level of social security in the digital society, each of the components must be considered in the light of its individual actions in the digital society and the multi-level overlapping of links between different objects and actors.

Let's make conditional logical-structural connections between threats: (Fig. 2):

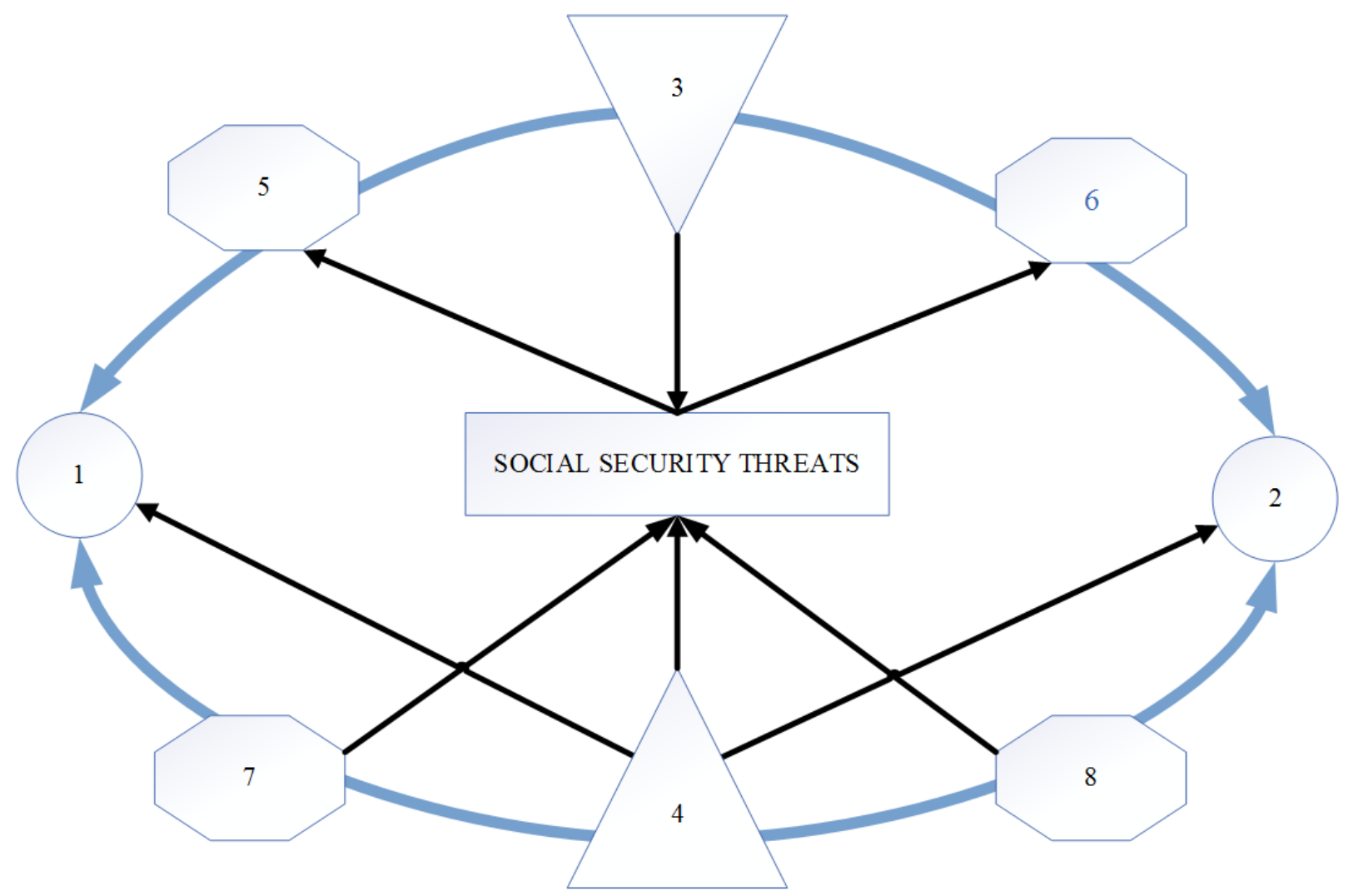

Fig. 2. Logical and structural connection between social security threats source: developed by the authors

where:

1-threats caused by shortcomings in policy and actions of state and political leaders, threats from government institutions;

2- threats related to national disputes, conflicts of interest of the center and regions, violation of the rights and freedoms of citizens, interethnic conflicts;

3-threats caused by violation of legal rights, freedoms to education, health care, inability of the state to protect them;

4-threats caused by the criminal situation, the growth of crime, including cybercrime;

5-threats caused by extremism, terrorism;

6-threats to public health as a result of deteriorating health care, medical care, the spread of infectious diseases, drug addiction, alcoholism, pandemics, mental illness;

7-threats related to the degradation of the population and the environment and livelihoods; 
8- threats are caused by qualitative changes of the HOMOSAPIENCE MAN, increase of egoists, quantitative changes of a demographic situation in the countries, regions, ethnicity.

At each level, an analysis should be conducted and integrated coefficients of social security assessment should be built, which will timely contribute to the necessary steps to prevent destabilization and social upheaval.

At the input of the proposed analysis, the above factors. The output is social transformation, namely: instability of social structures, processes of degradation, usurpation of power not only at the level of the state, regions, but also in families. We will consider this as an indicator of not only socio-security, but also an indicator of sociocybernetic security. For the next step of the analysis we enter 5 levels of social security (fig. 3)

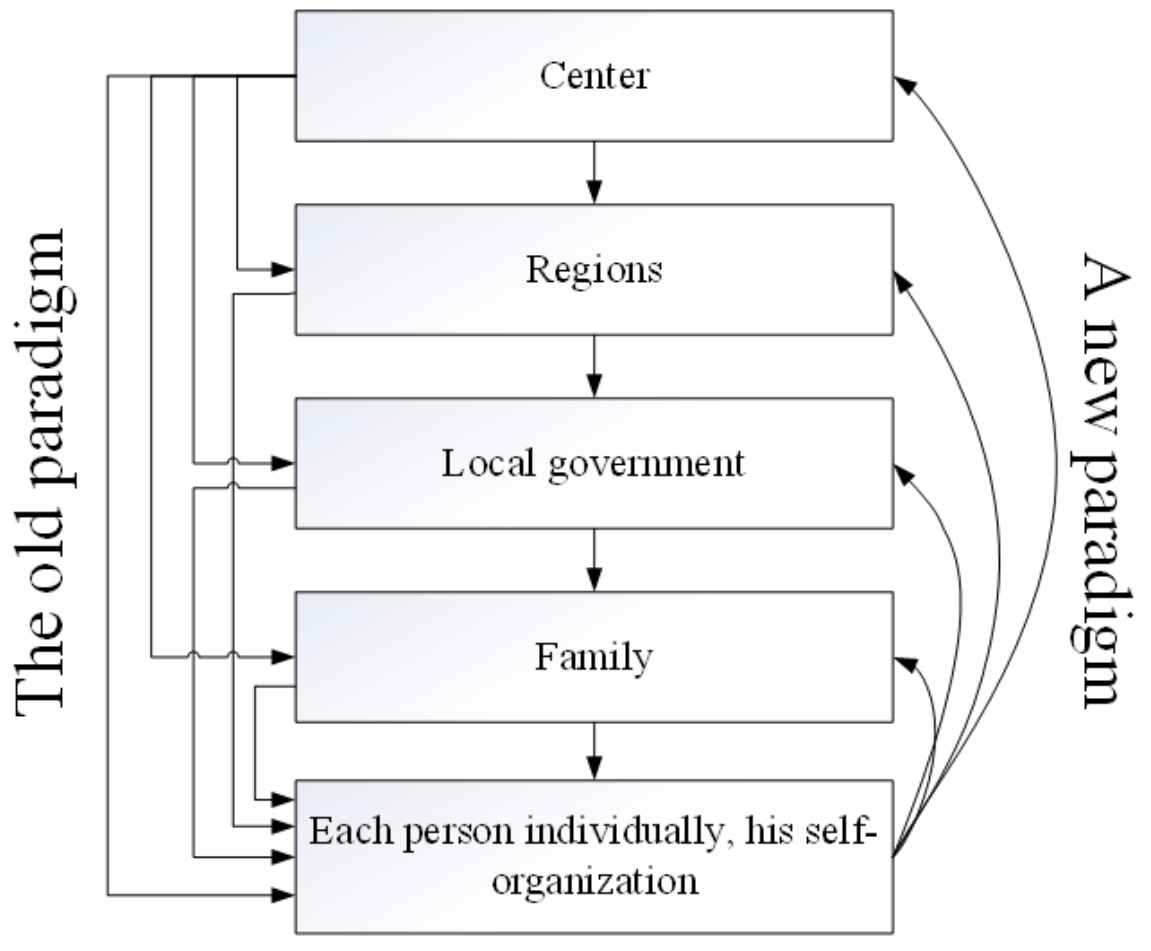

Fig.3. Levels of social security source: developed by the authors

At each of the levels, an analysis should be conducted and integrated coefficients of social security assessment should be built, which will timely contribute to the necessary steps to prevent destabilization and social upheaval.

In our work with the help of the constructed mathematical model another aspect of state capacity is analyzed: the problem of threats to social security. Depending on the condition (stable or unstable), there is a system that is characterized by a numerical integrated indicator (number of patients, number of those who 
passed the test, number of occupied beds in the hospital), social security in a broad and narrow sense, can to be considered and considered as being in a state of threat or protected.

Let the dynamical system be described by a first-order difference equation:

$$
x_{n+1}=x_{n}+\mu \mathrm{a}\left(\xi_{n}\right) x_{n}
$$

where a random process $\xi_{n}$ can take 2 states In the first state, the integral index is a positive number, and in the second state it is a negative number. The system can jump from one state to another. The function a, which depends on a random process, takes two values $\mathrm{a}_{1}, \mathrm{a}_{2}$ with probabilities $\mathrm{P}_{1}(n), P_{2}(n)$, that satisfy the following system of equations due to the Markov character of the described situation.

$$
\begin{gathered}
\mathrm{P}_{1}(n+1)=(1-\alpha) P_{1}(n)+\beta P_{2}(n), \\
\mathrm{P}_{2}(n+1)=\alpha P_{1}(n)+(1-\beta) P_{2}(n),
\end{gathered}
$$

where $0 \leq \alpha \leq 1,0 \leq \beta \leq 1$ i $0<\alpha+\beta<2$.

In this simple case from the mathematical point of view, we use the results of Dzhalladova (2009); Dzhalladova \& Růžičková (2020), where the moments of the equation for the random solution of system (1) are constructed. For partial moments $m_{k}(n)$ of the first order we have a system of difference equations:

$$
\begin{gathered}
m_{1}(n+1)=(1-\alpha)\left(1-\mu \mathrm{a}_{1}\right) m_{1}(n)+\beta\left(1+\mu \mathrm{a}_{2}\right) m_{2}(n), \\
m_{2}(n+1)=\alpha\left(1+\mu \mathrm{a}_{1}\right) m_{1}(n)+(1-\beta)\left(1+\mu \mathrm{a}_{2}\right) m_{1}(n) .
\end{gathered}
$$

We enter variables $m(n)=m_{1}(n)+m_{2}(n), v(n)=\frac{\beta m_{2}(n)-\alpha m_{1}(n)}{\alpha+\beta}$.

We obtain a system of difference equations:

$$
\begin{gathered}
m(n+1)=m(n)+\mu \frac{a_{1} \beta+a_{2} \alpha}{\alpha+\beta} m(n)+\mu\left(a_{2}-a_{1}\right) v(n), \\
v(n+1)=\mu\left(a_{1}-a_{2}\right) \frac{\alpha \beta(\beta+\alpha-1)}{(\alpha+\beta)^{2}} m(n)+(1-\alpha-\beta)(1+ \\
\left.\mu \frac{a_{1} \beta+a_{2} \alpha}{\alpha+\beta}\right) v(n)
\end{gathered}
$$


The system of equations (3) will be investigated for stability on average. The concept of stability on average is considered in Dzhalladova (2009). In the first approximation we find an integral set of solutions of system (4).

$$
v(n)=\mu\left(a_{1}-a_{2}\right) \frac{\alpha \beta(\beta+\alpha-1)}{(\alpha+\beta)^{2}} m(n)+O\left(\mu^{2}\right)
$$

and for the variable $m(n)$ find the equation:

$$
m(n+1)=\left(1+\mu \frac{a_{1} \beta+a_{2} \alpha}{\alpha+\beta}+\mu^{2} \frac{\left(a_{1}-a_{2}\right)^{2} \alpha \beta(1-\alpha-\beta)}{(\alpha+\beta)^{3}}+\mathrm{O}\left(\mu^{3}\right)\right) m(n),
$$

From equation (5) it follows that the zero solution of the difference equation (1) with random coefficients will be stable on average, if the condition:

$$
\mu \frac{a_{1} \beta+a_{2} \alpha}{\alpha+\beta}+\mu^{2} \frac{\left(a_{1}-a_{2}\right)^{2} \alpha \beta(1-\alpha-\beta)}{(\alpha+\beta)^{3}}+\mathrm{O}\left(\mu^{3}\right)<0,|\mu|>0
$$

Condition (6) will make it possible to answer the question of whether there is a threat to the social security of the country or it is under protection. Value $a_{1}, a_{2}, \alpha, \beta$ are set taking into account official statistics.

It should be noted that in more complex situations, such as complex virtualized cloud infrastructures with their dynamic nature Dzhalladova (2020), the application of instantaneous methods Mizumoto \& Chowell (2020) to a nonlinear system of difference equations is also studied, stability conditions are found, but application for real problems is rather cumbersome. Given the numerical methods and tools of computer mathematics, such attempts have been made and they are quite successful (Dzhalladova \& Kaminsky, 2020); Kaminsky \& Poliit (2020).

\section{CONCLUSIONS.}

Thus, the study of the stability in the mean and root mean square solutions of the differential equation with coefficients that depend on the discrete Markov process, thanks to the use of moment equations described in Dzhalladova \& Růžičková (2020), was reduced to solving systems of ordinary differential equations. The obtained approach is applied to the construction and analysis of conditions for the resilience of population recovery in a pandemic. 
The developed model can be used as a basis for determining optimized schemes to contain the epidemic and policies to mitigate its security consequences in Ukraine, to improve national legislation, the state security system and health care.

These results probably indicate certain contradictions: it seemed that on the one hand man, and on the other hand technical, cyber-physical mechanisms, the state. As if the person provides own safety, and on the other hand it is a mission of other structural components of system. But everything becomes clear after the analysis. Even in such a complex system as sociocybernetic security, the main atom is man, that is, the sociocybernetic system begins with human security, which, in fact, begins with man himself. Sociocybernetic security is the cornerstone of social policy, social culture, social rights, national security. Scientists have introduced the concept of social security Dzhalladova (2020), but it is new and insufficiently studied. Socioetal security is a concept that refers to the ability of the digital society to maintain its essence in a constantly changing environment and under real or imagined threats. Social security can be seen as part of sociocybernetic security. As social security is added as an element to the proposed sociocybernetic security system, it is clear that certain structural connections will change. Future research will show in which direction, but predictive system analysis gives hope that the system will be simpler and more convenient for algorithmization.

\section{Conflict of interests}

The authors declare no conflict of interest.

\section{References}

Borges Barbosa, R.; Henrique Costa, J.; Hadi, F. (2021). Economic and Ecological Rationalities: Uses and Abuses of the Political Exceptionality in the COVID-19 Pandemic. Economics. Ecology. Socium, vol. 5, pp.1-7.

Buckley, C., Clem, R., Herron, E. (2020) «National Security Implications of the COVID-19 Crisis: The Urgent Need to Build State Capacity». https://minerva.defense.gov/Owl-In-the-Olive-Tree/Owl_View/Article /2152823/nationalsecurity-implications-of-the-covid-19-crisis-the-urgent-need-to-build/

Dzhalladova I. (2009). A. Research stability of solutions of the systems linear with random coefficient. Studies of the university of Zilina MATHEMATICAL SERIES Zilina, Slovak Republik., Vol. 23/2009. P. 37-43.

Dzhalladova I., Růžičková, M. (2020). A Dynamical System with Random Structure and their Applications. Cambridge Scientific Publishers, 244 pp.

Dzhalladova I. A. (2020). Systemnyi analiz zahroz sotsiokibernetychnoi bezpeky v umovakh pandemii. Modeliuvannia ta informatsiini systemy v ekonomitsi. Vyp.100. S.50-58

Dzhalladova I. A., Kaminsky O. Ye. (2020). Stabilizing steps the security of human and society in the Covid-19 pandemic. Economics Business and Organization Research, p. 295-308 Retrieved from: https://dergipark.org.tr/en/pub/ebor/issue/58610/848963

Kaminsky O.Ye., Poliit D.H. (2020). Analiz dostovirnosti informatsii shchodo pandemii COVID-19 v Ukraini (na prykladi svitovykh ahrehatoriv danykh). Modeliuvannia ta informatsiini systemy v ekonomitsi. Vyp.100. S.83-93

Koval, V.; Sribna, Y.; Mykolenko, O.; Vdovenko, N. (2019). Environmental concept of energy security solutions of local communities based on energy logistics. 19th International Multidisciplinary Scientific GeoConference SGEM 2019, 19(5.3), 283-290. https://doi.org/0.5593/sgem2019/5.3/S21.036 
Migone, A.R. (2020) «The influence of national policy characteristics on COVID-19 containment policies: a comparative analysis». https://doi.org/10.1080/25741292.2020.1804660

Mizumoto K., Chowell G. (2020). Estimating Risk for Death from Coronavirus Disease, China, January-February 2020. Emerg Infect Dis. Jun;26(6): P.1251-1256. https://10.3201/eid2606.200233.

Pham, H. (2020). On Estimating the Number of Deaths Related to Covid-19. Rutgers University, Piscataway, Mathematics, 8(5), 655; https://doi.org/10.3390/math8050655

World Health Organization (1995). Revision and Updating of the International Health Regulations, WHA48.7, Fortyeighth World Health Assembly

World Health Organization (2005). Revision of the International Health Regulations, WHA58.3, Fifty-eighth World Health Assembly

Yan, B., Wang, J., Zhang, Z., Tang, X., Zhou Y. (2020). "An improved method for the fitting and prediction of the number of covid-19 confirmed cases based on lstm," Computers, Materials \& Continua, vol. 64, no.3, pp. 14731490.

About the authors
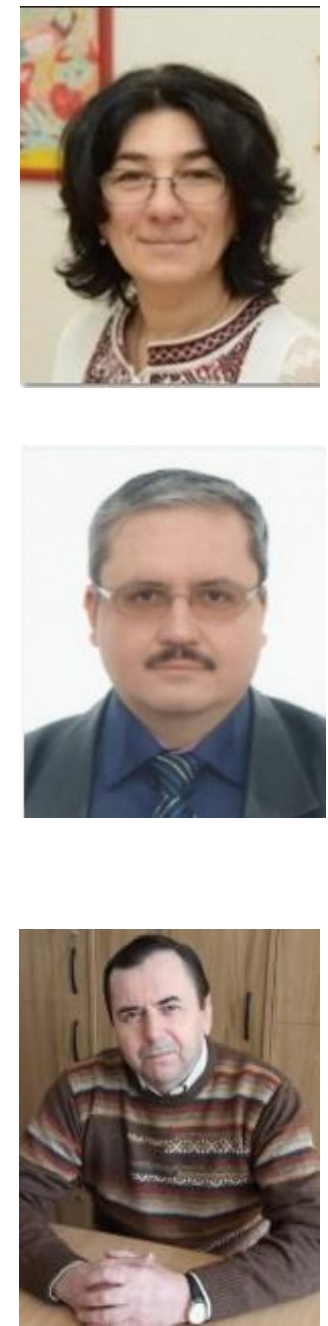

\section{Irada DZHALLADOVA}

Doctor of Mathematics, Professor, Head of the Department of Computer Mathematics and Information Security, Vadym Hetman Kyiv National Economic University Scopus Author ID: 8671668600

ORCID ID: https://orcid.org/0000-0003-3158-6844

\section{Oleh KAMINSKY}

Doctor of Economics, Associate Professor, Associate Professor of the Department of Computer Mathematics and Information Security, Vadym Hetman Kyiv National Economic University

ResearcherID: AAE-5167-2020

ORCID ID: https://orcid.org/0000-0003-0607-8944

\section{Oleksandr LUTYJ}

Candidate of Sciences in Technology, Associate Professor of the Department of Computer Mathematics and Information Security, Vadym Hetman Kyiv National Economic University

ORCID ID: https://orcid.org/0000-0002-1736-4180 